\title{
Attention, memory, visuoconstructive, and executive task performance in adolescents with anxiety disorders: a case-control community study
}

\author{
Desempenho em tarefas de atenção, memória, habilidades visuoconstrutivas e \\ funções executivas em adolescentes com transtornos de ansiedade: um estudo \\ comunitário caso-controle
}

\begin{abstract}
Rafaela Behs Jarros, ${ }^{1,2,3,4}$ Giovanni Abrahão Salum, 1,2,4 Cristiano Tschiedel Belem da Silva, ${ }^{1,4}$ Rudineia Toazza, ${ }^{1,5}$ Natália Becker, ${ }^{3}$ Marilyn Agranonik, ${ }^{6}$ Jerusa Fumagalli de Salles, ${ }^{3}$ Gisele Gus Manfro ${ }^{1,2,4}$
\end{abstract}

\begin{abstract}
Objective: The aim of the present study was to assess children and adolescents with mild and severe anxiety disorders for their performance in attention, verbal episodic memory, working memory, visuoconstructive skills, executive functions, and cognitive global functioning and conduct comparative analyses with the performance of children free from anxiety disorders.

Methods: Our sample comprised 68 children and adolescents aged 10 to 17 years ( 41 with current diagnoses of anxiety disorders and 27 controls) selected from a larger cross-sectional community sample of adolescents. Children and adolescents with anxiety disorders were categorized into two groups on the basis of anxiety severity (mild or severe). All participants underwent a neuropsychological assessment battery to evaluate attention, verbal episodic memory, working memory, visuoconstructive skills, and executive and cognitive functions. Results: No differences were found in any neuropsychological tests, with the single exception that the group with mild anxiety had better performance on the Digit Span backward test compared to subjects with severe anxiety and to controls ( $p=$ $0.041 ; \eta 2=0.11$ )

Conclusions: Not only might anxiety disorders spare main cognitive functions during adolescence, they may even enhance certain working memory processes.

Keywords: Neuropsychological assessment, anxiety disorders, cognitive functions, adolescents.
\end{abstract}

Resumo

Objetivo: Este estudo objetivou avaliar crianças e adolescentes com transtornos de ansiedade leve e moderada nas funções neuropsicológicas de atenção, memória episódica verbal, memória de trabalho, habilidades visuoconstrutivas, funções executivas e cognição global, comparando o seu desempenho ao de crianças com desenvolvimento típico.

Métodos: Participaram do estudo 68 crianças e adolescentes com idade de 10 a 17 anos (41 com diagnósticos clínicos atuais de transtornos de ansiedade e 27 controles), selecionados de uma amostra transversal mais ampla de adolescentes da comunidade. Os adolescentes com diagnóstico foram divididos ainda em dois grupos com base na gravidade dos transtornos (leve ou moderado). Todos os participantes realizaram uma avaliação neuropsicológica individual das funções de atenção, memória episódica verbal, memória de trabalho, habilidades visuoconstrutivas, funções executivas e cognição global. Resultados: Nenhum dos testes neuropsicológicas demonstrou diferenças significativas, sendo a única exceção a tarefa de span de dígitos ordem inversa, na qual o grupo com ansiedade leve apresentou desempenho superior ao do grupo com ansiedade moderada e também ao dos controles $\left(p=0.041 ; \eta^{2}=0.11\right)$.

Conclusão: Os resultados sugerem que não só os transtornos de ansiedade podem preservar as principais funções cognitivas durante a adolescência, mas que podem até melhorar certos processos de memória de trabalho.

Descritores: Avaliação neuropsicológica, transtornos de ansiedade, funções cognitivas, adolescentes.

\footnotetext{
${ }_{1}$ Programa de Transtornos de Ansiedade na Infância e Adolescência (PROTAIA), Serviço de Psiquiatria, Hospital de Clínicas de Porto Alegre (HCPA), Faculdade de Medicina, Departamento de Psiquiatria, Universidade Federal do Rio Grande do Sul (UFRGS), Porto Alegre, RS, Brazil. ${ }^{2}$ Instituto Nacional de Psiquiatria do Desenvolvimento para Crianças e Adolescentes (INPD), São Paulo, SP, Brazil. ${ }^{3}$ Núcleo de Estudos em Neuropsicologia Cognitiva (NEUROCOG), Departamento de Psicologia do Desenvolvimento e da Personalidade, Programa de Pós-Graduação em Psicologia, Instituto de Psicologia, UFRGS, Porto Alegre, RS, Brazil. ${ }^{4}$ Programa de Pós-Graduação em Ciências Médicas: Psiquiatria, Faculdade de Medicina, UFRGS, Porto Alegre, RS, Brazil. ${ }^{5}$ Programa de Pós-Graduação em Neurociências, Faculdade de Medicina, UFRGS, Porto Alegre, RS, Brazil. ${ }^{6}$ Núcleo de Estudos em Saúde da Criança e Adolescente (NESCA), HCPA, UFRGS, Porto Alegre, RS, Brazil.

Financial support: Fundo de Incentivo à Pesquisa e Eventos - Hospital de Clínicas de Porto Alegre (FIPE-HCPA).

Submitted Apr 26 2016, accepted for publication Sep 20 2016. No conflicts of interest declared concerning the publication of this article.

Suggested citation: Jarros RB, Salum GA, da Silva CT, Toazza R, Becker N, Agranonik M, et al. Attention, memory, visuoconstructive, and executive task performance in adolescents with anxiety disorders: a case-control community study. Trends Psychiatry Psychother. 2017;39(1):5-11. http://dx.doi. org/10.1590/2237-6089-2016-0032
} 


\section{Introduction}

Anxiety disorders are very common psychiatric diagnoses among adolescents ${ }^{1-3}$ and, unless adequately treated, they can seriously impair normal development $t^{4-7}$ and interfere with academic achievement and acquisition of social skills.

Many different mental processes have been associated with anxious behavior and some studies have suggested that neuropsychological assessment can be an important tool for increasing understanding of nosological aspects and treatment approaches in young people with anxiety. ${ }^{8}$ Whereas attentional bias related to emotional tasks is a core neuropsychological characteristic of anxiety disorders, ${ }^{8-11}$ the role of other neuropsychological functions is less clear. In comparison with other psychiatric disorders in childhood, such as attention deficit hyperactivity disorder (ADHD), the relationships between anxiety disorders and impairments affecting broad high order cognitive functions are extensively under-investigated. Additionally, neurocognitive research investigating pediatric anxiety is underdeveloped compared to research into adult anxiety. ${ }^{12}$ The majority of studies have investigated deficits in emotional processing rather than cognitive functions that can broadly impair emotional processing itself. $^{13}$ Furthermore, evidence from comparisons of these neuropsychological characteristics in children and adolescents with and without anxiety disorders is mixed.

Some neuropsychological studies with children and adolescents have demonstrated that deficits in attention, memory, and academic performance may be associated with anxiety disorders. ${ }^{14-17}$ Deficits in spatial working memory performance have been related to childhood anxiety, but not to the same extent as is seen in ADHD.18 Specifically, social anxiety disorder (SAD) was associated with visual memory ${ }^{19}$ and executive functioning impairments according to severity, ${ }^{20}$ and generalized anxiety disorder (GAD) was associated with deficits in attention. ${ }^{21}$ On the other hand, studies found no differences related to attention and verbal memory, ${ }^{22}$ or to performance monitoring and inhibition deficits, ${ }^{23}$ in children and adolescents with anxiety disorders. These cognitive deficits can be explained in terms of an increased activation of threat-related representations and a failure to use controlled processing to support the activation of alternate non-threatrelated representations, as described in the integrative theoretical framework. ${ }^{24}$ Some findings indicate that inhibitory control is impaired in trait anxiety children but not in state anxiety subjects. ${ }^{25}$ With regard to cognitive control processes (e.g., inhibition and working memory) it is important to note that they develop at different rates and could be sensitive to emotional disruption. ${ }^{12}$

In view of the contradictory results, further studies to evaluate neuropsychological functions in adolescents with anxiety disorders might be helpful. Moreover, although findings related to attentional bias suggested that anxiety severity influences cognitive deficits, ${ }^{10}$ very few studies have evaluated the role of anxiety severity in other neuropsychological functions. The inconsistent results of these studies could be due to comorbidities and the clinical severity of patients with anxiety disorders. Moreover, data on the relationship between clinical severity and neurocognitive functioning is scarce. ${ }^{20}$

Hence, the aim of this study is to compare the attention, verbal episodic memory, working memory, visuoconstructive skills, executive functions, and global cognitive functioning performance of individuals with mild and severe anxiety disorders to the performance of non-anxious controls in a community sample of adolescents. In view of what is reported by the studies reviewed, we expect to find that individuals with anxiety disorders have poorer performance, especially those whose symptoms are classified as severe. 12,19,20,22 $^{2}$

\section{Methods}

\section{Sample and procedure}

Our sample was selected from a larger crosssectional community sample comprising 10 to 17 -yearold adolescents from six different public schools who were screened for anxiety using the Screen for Child Anxiety Related Emotional Disorders (SCARED). ${ }^{23}$ A detailed description of the sample selection process can be found elsewhere. ${ }^{26}$

Adolescents were diagnosed according to a clinical interview, followed by a semi-structured diagnostic interview based on the Diagnostic and Statistical Manual of Mental Disorders, 4th edition (DSM-IV), the Schedule for Affective Disorders and Schizophrenia for School-Age Children - Present and Lifetime Version (K-SADS-PL). ${ }^{27}$ Six trained child psychiatrists or residents in psychiatry (kappa $=0.93$ across anxiety disorders) were responsible for psychiatric diagnostic assessments. The K-SADS$\mathrm{PL}$ was administered to the mother/father, followed by a direct interview with the adolescent. Best-estimate diagnoses were determined after a review of diagnoses, symptoms, and impairment levels by clinicians with experience in child psychiatry. Individuals were excluded if they had: 1) significant clinical illness; 2) history of affective bipolar disorder, pervasive developmental 
disorder, or any psychotic disorder; 3) clinical suspicion of mental retardation and 4) were not treatment-naive.

All non-medicated adolescents diagnosed with SAD, GAD, separation anxiety disorder, or panic disorder according to the diagnostic interview were selected as cases $(n=41)$. Moreover, individuals with anxiety disorders were categorized into two groups, based on the severity of their symptoms according to the Clinical Global Impressions (CGI): mild (CGI $\leq 4$ ) and severe anxiety (CGI > 4).28,29 Subjects with no anxiety disorders were considered controls ( $n=27$ ).

Adolescents diagnosed with specific phobia were considered cases only if the specific phobia occurred in comorbidity with any other anxiety disorder. Those with this condition alone were allocated to the control group, since specific phobia can be considered quite common during development, achieving spontaneous remission in most cases.30 Individuals with: 1) history of clinical illness (i.e., hypothyroidism); 2) history of bipolar disorder, pervasive developmental disorder, or any psychotic disorder; and 3) clinical suspicion of mental retardation were excluded.

All subjects were contacted later to conduct the neuropsychological assessment at their schools. Their parents provided written informed consent for participation in the study; adolescents also provided written consent themselves. The Research and Ethics Committee at the Hospital de Clínicas de Porto Alegre (protocol no. 08593) approved this study.

\section{Measures}

\section{Global cognitive functioning}

We used the Wechsler Abbreviated Scale of Intelligence (WASI). ${ }^{31}$ This scale was developed to assess verbal, nonverbal, and general cognitive functioning and to exclude intellectual disability. ${ }^{32,33}$

\section{Attention}

We used a cancellation task, the D2 test, ${ }^{34}$ to evaluate visual focused attention. The subject is expected as quickly and accurately as possible to cross off the target (double-traced d letter) each time it appears. The score is obtained as the difference between the raw score and the total number of errors.

\section{Working memory}

We used the Digit Span forward (DSF) and Digit Span backward (DSB) subtests from the Wechsler Intelligence Scale for Children, 4 th edition (WISC-IV). ${ }^{35}$ These subtests consist of eight digit sequences in the forward and seven in the backward directions, with a gradual increase in the number of digits in each span. The maximum score in these subtests is 30,16 for the forward and 14 for the backward sequences. ${ }^{36}$

\section{Verbal memory}

Two instruments were used: the logical memory I and II subtests from the Wechsler Memory Scale, 3rd edition (WMS-III)37 and the Rey Auditory Verbal Learning Test (RAVLT). ${ }^{38-40}$

The first of these tests was performed to evaluate the ability to learn and memorize conceptual material, presented in additive form. Subjects were asked to listen to a story and to recall it twice, first immediately and then again 30 minutes later. The maximum possible scores are 26 for the first story (A) and 25 for the second story (B).

The RAVLT consists of a single list of 15 words read loudly over five learning trials (I-V), which participants are required to freely recall after the administration of an interference list and after a 20-min delay. The RAVLT scores are the total number of words (maximum score: $15)$ recalled across five learning trials (I-V), the number of words (maximum score: 15) recalled following interference (VI) and the number of words recalled following a delay (VII).

\section{Visuoconstructive skills and non-verbal memory}

We used the Rey-Osterrieth Complex Figure test, which consists of copying and memory recall tasks using a complex geometric figure. ${ }^{41-43}$ Subjects are asked to copy a complex figure (Rey-Copy) and then, without being told in advance, to reproduce it from memory (Delayed Recall).16 We assessed the precision and location of each part of the complex figure. The maximum score on each task was 35 .

\section{Executive functions}

We used three instruments to assess executive functions. The first was a Go/no-go test, which is based on a paradigm of initiated or inhibited responses, depending on the stimulus that appears on a computer screen. ${ }^{44,45}$ Adolescents were asked to press a button whenever a blue $\mathrm{N}, \mathrm{J}$ or $\mathrm{W}$ or a red, green or yellow $\mathrm{O}$ appeared on the screen and to inhibit a response whenever a blue $\mathrm{O}$ or a pink $\mathrm{E}$ were presented as stimuli. The score was based on their total hits (maximum score: 96).

The second instrument was the Wisconsin Card Sorting Task (WCST) - computer-based version - which involves evaluation of abstract reasoning, cognitive flexibility and shifting cognitive strategies in response to environmental contingencies. ${ }^{46,47}$ Participants are asked to match each card that appears in the center of the 
screen to four different reference cards at the bottom of the screen. After matching each card to its corresponding reference card, participants receive positive (correct) or negative (incorrect) feedback. The pictures on the cards combine variations of shapes, colors, and numbers of figures printed. Subjects have to figure out the rationale behind combinations based on the computer feedback. Results are based on the total number of correct responses (maximum score: 60), perseverative errors (maximum score: 94), percent of conceptual level responses (maximum score: 100\%), and number of categories completed (maximum score: 6 ). ${ }^{16,47,48}$

The third executive function test was the Trail Making Test (TMT) A and $B_{1}{ }^{49}$ which is a test that evaluates processing speed, cognitive flexibility, visual search, and motor performance. ${ }^{50}$ Adolescents had to draw lines to connect randomly disposed numbers, in ascending order, from one to 25. The second part of the test (Trail B) consisted of linking numbers (1 to 13 ) and letters (A-L) in alternate ascending order. Participants were given five minutes to complete each trail. Results reported for both TMT $A$ and $B$ are the number of errors and the time in seconds. In both cases, Trail A and Trail B, the maximum score is 24 .

\section{Statistical analysis}

Data are expressed as means with standard deviations, and as relative and absolute frequencies. Analysis of variance (ANOVA) was conducted to compare neuropsychological performance results across the three groups. Pearson's chi-square was used to identify associations for categorical variables. Variables with asymmetric distribution were square-root transformed.

All differences in neuropsychological performance between the three groups that had $p$ values of less than 0.20 were included in a multivariate model of analysis of covariance (ANCOVA), controlling for possible confounders defined using the same statistical criterion or on the basis of theoretical relevance. Statistical analysis was performed using SPSS version 20.0 software. All tests were two-tailed and the effect size is presented as Partial Eta Squared. The overall level of significance adopted was a $=0.05$.

\section{Results}

Our sample comprised 68 participants, 41 adolescents with anxiety disorders ( 28 with mild and 13 with severe anxiety disorder) and 27 controls free from anxiety, who took part in the neuropsychological assessments. Anxiety diagnoses included GAD ( $n=29 ; 69.0 \%$ mild), separation anxiety disorder ( $n=17 ; 58.8 \%$ mild $)$, SAD ( $n=16 ; 43.7 \%$ mild) and panic disorder $(n=2 ; 100.0 \%$ mild). There were no significant differences between the three groups in age, gender, or sociodemographic variables. All groups were similar in terms of possible confounders, except for subjects with specific phobia, who differed significantly in terms of clinical severity (32.1\% mild cases, $53.8 \%$ severe cases and $14.8 \%$ controls; $p=0.037$ ) (Table 1 ).

Table 1 - Characteristics of anxiety and control groups

\begin{tabular}{|c|c|c|c|c|}
\hline & \multicolumn{3}{|c|}{ Clinical Global Impressions - Anxiety } & \multirow[b]{2}{*}{ p-value } \\
\hline & $\begin{array}{l}\text { Controls } \\
(n=27)\end{array}$ & $\begin{array}{c}\text { Mild } \\
(n=28)\end{array}$ & $\begin{array}{c}\text { Severe } \\
(n=13)\end{array}$ & \\
\hline Age & $12.6 \pm 1.96$ & $13.0 \pm 2.19$ & $12.2 \pm 1.21$ & $0.397^{*}$ \\
\hline Sex & & & & $0.493^{+}$ \\
\hline Female & $9(33.3)$ & $8(28.6)$ & $2(15.4)$ & \\
\hline Grade & & & & $0.640^{\ddagger}$ \\
\hline 4th & $1(3.7)$ & $3(10.7)$ & $2(15.4)$ & \\
\hline 5 th & $11(40.7)$ & $10(35.7)$ & $5(38.5)$ & \\
\hline 6 th & $4(14.8)$ & $2(7.1)$ & $3(23.1)$ & \\
\hline 7th & $7(25.9)$ & $2(7.1)$ & $1(7.7)$ & \\
\hline 8th & $1(3.7)$ & $8(28.6)$ & $2(15.4)$ & \\
\hline 1st to 3 rd (high school) & $3(11.1)$ & $3(10.7)$ & $0(0)$ & \\
\hline Socioeconomic status & & & & $0.837^{+}$ \\
\hline High/intermediate & $10(37)$ & $12(42.9)$ & $6(46.2)$ & \\
\hline Low & $17(63)$ & $16(57.1)$ & $7(53.8)$ & \\
\hline Attention deficit hyperactivity disorder & $9(33.3)$ & $4(14.3)$ & $5(38.5)$ & $0.153 \dagger$ \\
\hline Specific phobia & $4(14.8)$ & $9(32.1)$ & $7(53.8)$ & $0.037+$ \\
\hline Oppositional defiant disorder & $5(18.5)$ & $4(14.3)$ & $1(7.7)$ & $0.749+$ \\
\hline Depression & $0(0)$ & $1(3.6)$ & $2(15.4)$ & $0.091^{\S}$ \\
\hline Post-traumatic stress disorder & $0(0)$ & $0(0)$ & $1(7.7)$ & $0.191^{\S}$ \\
\hline
\end{tabular}

Data presented as $\mathrm{n}(\%)$ or mean \pm standard deviation.

p-values: * analysis of variance (ANOVA); ${ }^{+}$Pearson's chi-square; ${ }^{\ddagger}$ Pearson's chi-square tendency; ${ }^{\S}$ Fisher's exact test.

8 - Trends Psychiatry Psychother. 2017;39(1) 
In the bivariate analyses, participants with mild anxiety performed better in the Digit Span backward task than controls and than subjects with severe anxiety disorder $(p=0.015)$. There were no significant differences detected between mildly and severely anxious individuals and controls, even collapsing mild and severe groups into a single anxiety category.

Table 2 lists mean values for all neuropsychological tests for adolescents with mild and severe anxiety disorders and for those in the control group. We performed an ANCOVA in order to control for possible confounders to our findings (age, gender, sociodemographic variables, WASI [total score], attention deficit hyperactivity disorder, and specific phobia). Even after statistical control the difference in the Digit Span backward persisted ( $p=0.041 ; \eta 2=0.11$ ), with a small effect size. The mild anxiety group had better performance than the other two groups, which, in turn, did not differ from each other. Although adolescents with severe anxiety had worse performance than the mild anxiety group, they did not have deficits when compared to controls.

Table 2 - Bivariate analysis comparing performance in neuropsychological tests across the three groups

\begin{tabular}{|c|c|c|c|c|c|}
\hline \multirow[b]{3}{*}{ Cognitive functions and tests } & \multicolumn{3}{|c|}{ Clinical Global Impressions - Anxiety } & \multirow[b]{3}{*}{$\mathbf{F}$} & \multirow[b]{3}{*}{ p-value* } \\
\hline & $\begin{array}{l}\text { Controls } \\
(n=27)\end{array}$ & $\begin{array}{c}\text { Mild } \\
(n=28) \\
\end{array}$ & $\begin{array}{c}\text { Severe } \\
(n=13)\end{array}$ & & \\
\hline & Mean \pm SD & Mean \pm SD & Mean \pm SD & & \\
\hline \multicolumn{6}{|l|}{ Attention } \\
\hline D2 & $164.6 \pm 94.60$ & $178.5 \pm 83.05$ & $154.4 \pm 88.49$ & 0.37 & 0.693 \\
\hline \multicolumn{6}{|l|}{ Working memory } \\
\hline Digit Span forward & $8.0 \pm 1.82$ & $8.1 \pm 1.96$ & $7.1 \pm 2.23$ & 1.33 & $0.271^{+}$ \\
\hline Digit Span backward & $3.7 a \pm 1.66$ & $5.4 \mathrm{~b} \pm 2.38$ & $4.1 \mathrm{a} \pm 1.90$ & 4.52 & $0.015^{+}$ \\
\hline \multicolumn{6}{|l|}{ Verbal memory } \\
\hline WMS A+ B (immediate) & $21.2 \pm 5.35$ & $23.4 \pm 7.19$ & $21.2 \pm 8.71$ & 0.85 & 0.434 \\
\hline WMS A +B (delayed) & $18.3 \pm 5.41$ & $21.5 \pm 6.45$ & $18.5 \pm 7.23$ & 2.03 & 0.140 \\
\hline RAVLT (1st list) & $5.1 \pm 1.51$ & $5.1 \pm 1.32$ & $4.8 \pm 2.01$ & 0.20 & 0.819 \\
\hline RAVLT (7th list) & $10.0 \pm 2.65$ & $10.0 \pm 2.91$ & $9.1 \pm 2.05$ & 0.69 & 0.507 \\
\hline \multicolumn{6}{|l|}{ Visuoconstructive skills } \\
\hline Rey complex figure copy & $27.5 \pm 5.00$ & $30.0 \pm 4.44$ & $30.6 \pm 3.81$ & 2.94 & 0.060 \\
\hline Rey complex figure from memory & $16.8 \pm 5.72$ & $18.8 \pm 7.83$ & $16.1 \pm 5.60$ & 1.02 & 0.368 \\
\hline \multicolumn{6}{|l|}{ Executive functions } \\
\hline Trail A (time) & $66.5 \pm 20.95$ & $61.1 \pm 18.35$ & $72.4 \pm 22.46$ & 1.45 & 0.243 \\
\hline Trail A (errors) & $0.1 \pm 0.73$ & $0.1 \pm 0.63$ & $0.1 \pm 1.19$ & 0.15 & $0.860^{+}$ \\
\hline Trail B (time) & $132.5 \pm 53.00$ & $125.4 \pm 42.79$ & $142.9 \pm 46.76$ & 0.61 & 0.548 \\
\hline Trail B (errors) & $0.2 \pm 1.25$ & $0.1 \pm 1.21$ & $0.3 \pm 1.29$ & 0.42 & $0.662^{+}$ \\
\hline Wisconsin - total number correct & $81.1 \pm 11.85$ & $78.6 \pm 13.17$ & $77.7 \pm 13.53$ & 0.43 & 0.655 \\
\hline Wisconsin - perseverative errors & $17.3 \pm 6.76$ & $18.3 \pm 9.52$ & $20.7 \pm 9.68$ & 0.72 & 0.489 \\
\hline $\begin{array}{l}\text { Wisconsin - percent conceptual level } \\
\text { responses }\end{array}$ & $62.3 \pm 14.30$ & $59.1 \pm 18.46$ & $56.0 \pm 17.67$ & 0.67 & 0.516 \\
\hline $\begin{array}{l}\text { Wisconsin - number of categories } \\
\text { completed }\end{array}$ & $4.3 \pm 1.61$ & $4.4 \pm 1.85$ & $3.7 \pm 1.94$ & 0.64 & $0.529^{+}$ \\
\hline Go/no-go & $82.1 \pm 5.61$ & $80.3 \pm 7.25$ & $80.5 \pm 8.03$ & 0.54 & 0.583 \\
\hline \multicolumn{6}{|l|}{ Global cognitive functioning } \\
\hline WASI & $118.7 \pm 27.25$ & $112.6 \pm 27.98$ & $100.8 \pm 18.68$ & 2.04 & 0.139 \\
\hline
\end{tabular}

Data presented as $\mathrm{n}$ and mean \pm standard deviation.

F = F-statistic (F-ratio); RAVLT = Rey Auditory Verbal Learning Test; SD = standard deviation; WASI = Wechsler Abbreviated Scale of Intelligence; WMS = Wechsler Memory Scale.

* p-value according to analysis of variance (ANOVA); means followed by the same letter do not differ according to the test of minimum significant difference;

$+\mathrm{p}$-value in ANOVA, square-root transformed.

\section{Discussion}

In contradiction of our initial hypothesis, we found no significant differences between the groups in most of the neuropsychological tests that were administered. Our study, in contrast with others, ${ }^{12,16,18,19}$ evaluated the participants using a large neuropsychological battery that covered many cognitive functions (attention, verbal episodic memory, working memory, visuoconstructive skills, executive functions, and cognitive global functioning) within a small sub-sample from a larger, non-medicated, community sample diagnosed with anxiety disorders according to the DSM-IV criteria.

However, our study demonstrated that people with mild anxiety may perform better in the Digit Span backward, which is used to evaluate attention and 
working memory, on the basis of comparison to controls and to a group with severe anxiety. Notwithstanding, subjects with severe anxiety did not outperform controls in the same task. This result did not corroborate our initial hypothesis and contrasts with findings from previous studies that have suggested that poor academic performance in children with anxiety could be partially mediated by a deficit in verbal working memory, ${ }^{51}$ since working memory has been found to be positively associated with learning ability and with academic achievement, especially in childhood. ${ }^{51-53}$ Despite applying the same neuropsychological test, these authors did not evaluate clinical psychiatric diagnoses and neither did they rate anxiety severity.

Notwithstanding, studies have demonstrated that children with GAD may have poorer verbal memory, whereas children with social phobia may exhibit more omissions in a continuous performance task than healthy controls. ${ }^{16}$ Furthermore, we can hypothesize that adolescents with mild anxiety might have been more able to use their anxiety in a functional way as compared to adolescents with severe anxiety and controls, possibly mediated by better inhibitory control. In support of this last statement, previous studies have demonstrated an absence of inhibitory control impairment in state anxiety subjects. ${ }^{25}$ Inhibitory control is one of the main functions of the prefrontal cortex and is important to the ability to resist task-irrelevant stimuli. ${ }^{54}$ Additionally, we can also hypothesize that children with mild anxiety do not have amygdala hyper-responsivity and prefrontal underrecruitment. ${ }^{24}$ Finally, in this study we did not attempt to evaluate the impact of socioeconomic status on the cognitive development of children with anxiety disorders.

Our research contributes important additional data to research into anxiety disorders, since all subjects were evaluated with extensive psychiatric assessments and neuropsychological testing. However, some limitations must be considered, such as the small sample size, which limits the statistical analyses. Furthermore, results were not controlled for multiple testing, which could have biased our positive findings. Additionally, it is important to note that our control group had other psychiatric comorbidities, which could have biased our results toward the null. Along the same lines, our sample had a significant burden of comorbidities, i.e., ADHD, which could influence the results. Specifically, with regard to ADHD symptoms it is important to point out that one third of our control group exhibited these symptoms. A recent meta-regression study concluded that global lifetime prevalence of ADHD was $9 \%,{ }^{55}$ lower than the prevalence observed here. Irrespective of this limitation, we statistically controlled our results for confounders, including $A D H D$, but it is important to hypothesize that the mild anxiety group could have performed better in working memory tests because of its lower frequency of ADHD symptoms compared to the control group.

There is little evidence acquired by conducting neuropsychological testing in anxiety disorders among adolescents. The few studies that have been published report results for cognitive functions other than memory or attentional bias. ${ }^{8-11,16,19,22}$ Our study therefore provides preliminary evidence that neuropsychological deficits may not be remarkable features of anxiety disorders in adolescence. Future studies should increase sample sizes in order to be able test with multivariate models, i.e., logistic regression, that could better explain the results reported here.

\section{Acknowledgements}

Rafaela Behs Jarros receives a Masters scholarship from Coordenação de Aperfeiçoamento de Pessoal de Nível Superior (CAPES). Giovanni Abrahão Salum receives a scholarship from Fundação de Amparo à Pesquisa do Estado do Rio Grande do Sul (FAPERGS) and CAPES. Cristiano Tschiedel Belem da Silva receives a post-doctoral scholarship from CAPES. Rudineia Toazza and Marilyn Agranonik receive doctoral scholarships from CAPES. Natália Becker receives a doctoral scholarship from Conselho Nacional de Desenvolvimento Científico e Tecnológico (CNPq). Jerusa Fumagalli de Salles and Gisele Gus Manfro receive senior researcher scholarships from CNPq.

\section{References}

1. Costello EJ, Angold A. Epidemiology. In: March JS, editor. Anxiety disorders in children and adolescents. New York: Guilford; 1995. p. 109-24.

2. Costello EJ, Mustillo S, Erkanli A, Keeler G, Angold A. Prevalence and development of psychiatric disorders in childhood and adolescence. Arch Gen Psychiatry. 2003;60:837-44.

3. Merikangas KR, He JP, Burstein M, Swanson SA, Avenevoli S, Cui L, et al. Lifetime prevalence of mental disorders in U.S. adolescents: results from the National Comorbidity Survey Replication--Adolescent Supplement (NCS-A). J Am Acad Child Adolesc Psychiatry. 2010;49:980-9.

4. Kessler RC, McGonagle KA, Zhao S, Nelson CB, Hughes M, Eshleman $S$, et al. Lifetime and 12-month prevalence of DSM-III-R psychiatric disorders in the United States. Results from the National Comorbidity Survey. Arch Gen Psychiatry. 1994;51:8-19.

5. Pine DS. Childhood anxiety disorders. Curr Opin Pediatr. 1997;9:32938.

6. Sylvester CS. Separation anxiety disorder and other anxiety disorders. In: Kaplan HI, Sadock JB, editors. Comprehensive textbook of psychiatry. 7th ed. Washington: Lippincott Williams \& Wilkins; 2000. p. 2770-3.

7. Saraceno B. The WHO World Health Report 2001 on mental health. Epidemiol Psichiatr Soc. 2002;11:83-7.

8. Pine DS, Mogg K, Bradley BP, Montgomery L, Monk CS, McClure E, et al. Attention bias to threat in maltreated children: implications for vulnerability to stress-related psychopathology. Am J Psychiatry. 2005; 162:291-6 
9. Roy AK, Vasa RA, Bruck M, Mogg K, Bradley BP, Sweeney M, et al. Attention bias toward threat in pediatric anxiety disorders. J Am Acad Child Adolesc Psychiatry. 2008;47:1189-96.

10. Waters AM, Mogg K, Bradley BP, Pine DS. Attentional bias for emotional faces in children with generalized anxiety disorder. J Am Acad Child Adolesc Psychiatry. 2008;47:435-42.

11. Monk CS, Nelson EE, McClure EB, Mogg K, Bradley BP, Leibenluft E, et al. Ventrolateral prefrontal cortex activation and attentional bias in response to angry faces in adolescents with generalized anxiety disorder. Am J Psychiatry. 2006;163:1091-7.

12. Mueller SC, Shechner T, Rosen D, Nelson EE, Pine DS, Ernst M. Incidental threat during visuospatial working memory in adolescent anxiety: an emotional memory-guided saccade task. Depress Anxiety. 2015;32:289-95

13. Ferrari F, Lapp LK, Peretti CS. Current research on cognitive aspects of anxiety disorders. Curr Opin Psychiatry. 2011;24:49-54.

14. Benjamin R, Costello EJ, Warren M. Anxiety disorder in a pediatric sample. J Anxiety Disord. 1990;4:293-316

15. Toazza R, Salum GA, Flores SM, Jarros RB, Pine DS, de Salles JF, et al. Phonemic verbal fluency is associated with pediatric anxiety disorders: evidence from a community study. J Child Adolesc Psychopharmacol. 2014;24:149-57.

16. Toren $P$, Sadeh $M$, Wolmer $L$, Eldar $S$, Koren $S$, Weizman $R$, et al. Neurocognitive correlates of anxiety disorders in children: a preliminary report. J Anxiety Disord. 2000;14:239-47.

17. Micco JA, Henin A, Biederman J, Rosenbaum JF, Petty C, Rindlaub $L A$, et al. Executive functioning in offspring at risk for depression and anxiety. Depress Anxiety. 2009;26:780-90.

18. Vance A1, Ferrin M, Winther J, Gomez R. Examination of spatial working memory performance in children and adolescents with attention deficit hyperactivity disorder, combined type (ADHD-CT) and anxiety. J Abnorm Child Psychol. 2013;41:891-900.

19. Vasa RA, Roberson-Nay R, Klein RG, Mannuzza S, Moulton JL 3rd, Guardino $M$, et al. Memory deficits in children with and at risk for anxiety disorders. Depress Anxiety. 2007;24:85-94.

20. Fujii Y, Kitagawa N, Shimizu Y, Mitsui N, Toyomaki A, Hashimoto N, et al. Severity of generalized social anxiety disorder correlates with low executive functioning. Neurosci Lett. 2013;543:42-6.

21. Kendall PC, Pimentel SS. On the physiological symptom constellation in youth with Generalized Anxiety Disorder (GAD). J Anxiety Disord. 2003; 17:211-21.

22. Günther T, Holtkamp K, Jolles J, Herpertz-Dahlmann B, Konrad K. Verbal memory and aspects of attentional control in children and adolescents with anxiety disorders or depressive disorders. J Affect Disord. 2004;82:265-9.

23. Isolan L, Salum GA, Osowski AT, Amaro E, Manfro GG. Psychometric properties of the Screen for Child Anxiety Related Emotional Disorders (SCARED) in Brazilian children and adolescents. J Anxiety Disord. 2011;25:741-8.

24. Bishop SJ. Neurocognitive mechanisms of anxiety: an integrative account. Trends Cogn Sci. 2007;11:307-16.

25. Ursache A, Raver CC. Trait and state anxiety: relations do executive functioning in an at risk sample. Cog Emot. 2014;28:845-55.

26. Salum GA, Isolan LR, Bosa VL, Tocchetto AG, Teche SP, Schuch I, et al. The multidimensional evaluation and treatment of anxiety in children and adolescents: rationale, design, methods and preliminary findings. Rev Bras Psiquiatr. 2011;33:181-95.

27. Kaufman J, Birmaher $B$, Brent $D$, Rao U, Flynn C, Moreci $P$, et al. Schedule for Affective Disorders and Schizophrenia for School-Age Children-Present and Lifetime Version (K-SADS-PL): initial reliability and validity data. J Am Acad Child Adolesc Psychiatry. 1997;36:9808.

28. Busner J, Targum SD. The clinical global impressions scale: applying a research tool in clinical practice. Psychiatry (Edgmont). 2007;4:2837.

29. Busner J, Targum SD, Miller DS. The Clinical Global Impressions scale: errors in understanding and use. Compr Psychiatry. 2009;50:257-62.

30. Klein RG. Anxiety disorders. ] Child Psychol Psychiatry. 2009;50:15362.

31. Yates DB, Trentini CM, Tosi SD, Corrêa SK, Poggere LC, Valli F. Apresentação da escala de inteligência Wechsler abreviada (WASI). Aval Psicol. 2006;5:227-33.

32. Strauss $E$, Sherman E, Spreen O. A compendium of neuropsychological test: administration, norms and commentary. 3th ed. New York: Oxford University; 2006.

33. Heck VS, Yates DB, Poggere LC, Tosi SD, Bandeira DR, Trentini CM. Validação dos subtestes verbais da versão de adaptação da WASI. Aval Psicol. 2009;8:33-42.

34. Brickenkamp R. Teste D2: atenção concentrada: manual, instruções, avaliação e interpretação. São Paulo: Centro Editor de Testes e
Pesquisas Psicológicas; 2000.

35. Wechsler D. Wechsler Intelligence Scale for Children-Third edition (WISC-III): Manual. San Antonio: Psychological Corp; 1991.

36. Figueredo VLM, Nascimento E. Desempenhos nas duas tarefas do subteste dígitos do WISC-III e do WAIS-III. Psic Teor e Pesq. 2007;23:313-8.

37. Wechsler D. Wechsler memory scale - revised manual. New York: The Psychological Corp; 1987.

38. Rey AL. Examen Clinique en Psychologie. Paris: Universitaire de France; 1958.

39. Malloy-Diniz LF, Lasmar VA, Gazinelli Lde S, Fuentes D, Salgado JV. The Rey Auditory-Verbal Learning Test: applicability for the Brazilian elderly population. Rev Bras Psiquiatr. 2007;29:324-9.

40. Magalhães SS, Hamdan AC. The Rey Auditory Verbal Learning Test: normative data for the Brazilian population and analysis of the influence of demographic variables. Psychol Neurosci (Online). 2010;3:85-91.

41. Rey A. Figuras complexas de Rey: teste de cópia e de reprodução de memória de figuras geométricas complexas. São Paulo: Casa do Psicólogo; 1999.

42. Osterrieth PA. Le test de copie d'une figure complexe. Clin Neuropsychol 1944;7:9-15.

43. Oliveira MS, Rigoni MS. Figuras Complexas de Rey: teste de cópia e de reprodução de figuras geométricas complexas. São Paulo: Casa do Psicólogo; 2010.

44. Bannon S, Gonsalvez CJ, Croft RJ, Boyce PM. Response inhibition deficits in obsessive-compulsive disorder. Psychiatry Res. 2002;110:165-74.

45. Malloy-Diniz LF, Sedo M, Fuentes D, Leite WB. Neuropsicologia das funções executivas. In: Fuentes D, Malloy-Diniz LF, Camargo CHP, Cosenza RM, editors. Neuropsicologia: teoria e prática. Porto Alegre: Artmed; 2008. p. 187-206.

46. Heaton RK, Chelune GJ, Taley JL, Kay GG, Curtiss G. Wisconsin Card Sorting Test Manual (Revised and expanded). Odessa: Psychological Assessment Resources; 1996.

47. Cunha JA, Trentini CM, Argimon IL, Oliveira MS, Werlang BG, Prieb RG. Teste Wisconsin de classificação de cartas. São Paulo: Casa do Psicólogo; 2004.

48. Wagner GP, Trentini CM. Assessing executive functions in older adults: a comparison between the manual and the computer-based versions of the Wisconsin Card Sorting Test. Psychol Neurosci (Online). 2009;2:195-8.

49. Reitan RM, Wolfson D. The Halstead-Reitan neuropsychology battery: theory and clinical interpretation. Hardcover: Neuropsychology; 1993.

50. Perianez JA, Rios-Lago M, Rodriguez-Sanchez JM, Adrover-Roig D, Sanchez-Cubillo I, Crespo-Facorro B, et al. Trail Making Test in traumatic brain injury, schizophrenia, and normal ageing: sample comparisons and normative data. Arch Clin Neuropsychol. 2007; 22:433-47

51. Wens J, Vermeire $E$, Hearnshaw $H$, Lindenmeyer A, Biot $Y$, Van Royen $\mathrm{P}$. Educational interventions aiming at improving adherence to treatment recommendations in type 2 diabetes: a sub-analysis of a systematic review of randomised controlled trials. Diabetes Res Clin Pract. 2008;79:377-88.

52. Gathercole SE, Alloway TP, Willis C, Adams AM. Working memory in children with reading disabilities. J Exp Child Psychol. 2006;93:26581.

53. Alloway TP, Gathercole SE, Kirkwood H, Elliott J. The cognitive and behavioral characteristics of children with low working memory. Child Dev. 2009;80:606-21.

54. Miyake A, Friedman NP, Emerson MJ, Witzki AH, Howerter, Wager TD. The unity and diversity of executive functions and their contributions to complex "frontal lobe" tasks: a latent variable analysis. Cogn Psychol. 2000;41:49-100.

55. Polanczyk GV, Willcutt EG, Salum GA, Kieling C, Rohde LA. ADHD prevalence estimates across three decades: An updated systematic review and meta-regression analysis. Int J Epidemiol. 2014;43:43442.

\section{Correspondence:}

Natalia Becker

Universidade Federal do Rio Grande do Sul (UFRGS)

Rua Ramiro Barcelos, 2600, sala 114

90035-003 - Porto Alegre, RS - Brazil

Tel./Fax: +55 (51) 3308.5341/ +55 (51) 3023.6184

E-mail: natxib@gmail.com 